\title{
Comparison of autonomic activity between pre and post menstrual period
}

\author{
Jyoti Sahebrao Kale ${ }^{1}$, Nilesh Tulsiram Katole ${ }^{2 *}$
}

\begin{abstract}
${ }^{1}$ Department of Physiology, Lokmanya Tilak Municipal Medical College and General Hospital, Sion, Mumbai-22, Maharashtra, India

${ }^{2}$ Department of Pharmacology, Lokmanya Tilak Municipal Medical College and General Hospital, Sion, Mumbai-22, Maharashtra, India
\end{abstract}

Received: 09 February 2015

Accepted: 01 March 2015

\section{*Correspondence:}

Dr. Nilesh Tulsiram Katole,

E-mail: nilesh.katole@gmail.com

Copyright: () the author(s), publisher and licensee Medip Academy. This is an open-access article distributed under the terms of the Creative Commons Attribution Non-Commercial License, which permits unrestricted non-commercial use, distribution, and reproduction in any medium, provided the original work is properly cited.

\begin{abstract}
Background: Autonomic nervous system play important role in premenstrual stress. In present study we compare autonomic functions between premenstrual and postmenstrual phases in young females.

Methods: The study was carried out on 50 eumenorrheic healthy female of 17 to 25 years of age observed on pre and post menstruation. Autonomic parameters like basal pulse rate, basal blood pressure and cold stimulus test was carried out in pre and post menstrual phases. Data was analyzed by using paired t-test.

Results: There was significant increase $(\mathrm{P}<0.001)$ in pulse rate, blood pressure, systolic and diastolic response to cold stimulus during premenstrual period as compared to postmenstrual period.

Conclusions: There was significant increase $(\mathrm{P}<0.001)$ in pulse rate, blood pressure, systolic and diastolic response to cold stimulus during premenstrual period as compared to postmenstrual period.
\end{abstract}

Keywords: Premenstruation, Autonomic function, Cold pressor test, Sympathetic activity

\section{INTRODUCTION}

Premenstrual Syndrome is a wide variety of cyclic, recurrent, physical, emotional, behavioral symptoms occurring during late luteal phase of menstrual cycle and abating shortly following beginning of menses in early follicular phase of menstruation. ${ }^{1}$ It is a major clinical entity affecting large segment of female population. Many behavioral and neurological symptoms like headache, malaise, nervous irritability, emotional instability, decrease in the ability to concentrate, resulting in impaired motor co-ordination are reported during premenstrual phase. ${ }^{2}$ Along with hormonal changes, stress is also a major cause of premenstrual syndrome. Stress causes disturbance in balance of sympathetic and parasympathetic nervous system. Changes in heart rate and blood pressure are the most important physiological responses following stress. ${ }^{3,5}$ Cold pressor test is a standard test to assess the sympathetic activity. ${ }^{4}$ The present study was carried out to study effect of premenstrual stress on autonomic function in young females.

\section{METHODS}

The study was carried out on 50 normal healthy females 17 to 25 years of age. Their detailed menstrual history was noted and premenstrual and postmenstrual phase calculated. Premenstrual phase was taken as 1 to 7 days prior to the expected date of next menstruation and postmenstrual phase as $5^{\text {th }}$ to $10^{\text {th }}$ day of menstruation. Ethics committee clearance was taken and Informed consent was obtained. Autonomic parameters like basal pulse rate, basal blood pressure and cold pressor test was 
used to asses autonomic activity. Cold pressor test was done in supine posture with left wrist immersed in cold water having temp. $4^{\circ} \mathrm{C}$ for $1 \mathrm{~min}$. Heart rate, systolic blood pressure, diastolic BP was recorded in Right hand after $1 \mathrm{~min}$ and $5 \mathrm{~min}$. The maximum changes in systolic and diastolic BP from resting value during cold stimulus is defined as systolic and diastolic response.

Table 1: Inclusion and exclusion criteria.

\begin{tabular}{|ll|}
\hline Inclusion criteria & Exclusion criteria \\
\hline Normal healthy females & Married females \\
\hline $\begin{array}{l}\text { Women with regular } \\
\text { menstrual cycle }\end{array}$ & Any gynecological disorders \\
\hline & Any acute or chronic illness \\
\hline & Subjects on long term medication \\
\hline & $\begin{array}{l}\text { Subjects with metabolic and } \\
\text { endocrine disorders }\end{array}$ \\
\hline & Smokers \& alcoholic \\
\hline & Subjects with psychiatric disorders \\
\hline
\end{tabular}

\section{Statistical analysis}

It was done by student paired " $\mathrm{t}$ " test. $\mathrm{P}<0.001$ was considered as statistically significant.

\section{RESULTS}

In Table 2, the autonomic function tests for sympathetic activity were compared during pre and post menstrual phases. It was observed that pulse rate, blood pressure and cold pressor test were statistically more significant $(\mathrm{P}$ $<0.001$ ), in premenstrual phase as compared to post menstrual phase.

Table 2: Comparison of autonomic functions pre and post menstruation phase.

\begin{tabular}{|c|c|c|c|}
\hline \multicolumn{2}{|c|}{ Parameters } & $\begin{array}{l}\text { Pre } \\
\text { menstruation } \\
\text { phase }\end{array}$ & $\begin{array}{l}\text { Post } \\
\text { menstruation } \\
\text { phase }\end{array}$ \\
\hline \multicolumn{2}{|c|}{ Pulse rate (beats/min) } & $84.9 \pm 9.6$ & $80.4 \pm 9.1^{*}$ \\
\hline \multicolumn{2}{|c|}{ Systolic BP (mmHg) } & $115.0 \pm 11$ & $109 \pm 10^{*}$ \\
\hline \multicolumn{2}{|c|}{ Diastolic BP (mmHg) } & $72.6 \pm 9.2$ & $69.7 \pm 8.3^{*}$ \\
\hline \multirow{2}{*}{$\begin{array}{l}\text { Cold } \\
\text { pressor } \\
\text { test }\end{array}$} & Systolic BP & $131.2 \pm 9.6$ & $118.2 \pm 8.6^{*}$ \\
\hline & Diastolic BP & $77.4 \pm 9.2$ & $74.3 \pm 8.6^{*}$ \\
\hline
\end{tabular}

Values are mean $\pm \mathrm{SD}, \mathrm{n}=50, * \mathrm{P}<0.001$

\section{DISCUSSION}

Significantly higher values in pulse rate, systolic and diastolic blood pressure and cold pressor test during premenstrual phase as compared to post menstrual phase shows increased activity of sympathetic system during premenstrual phase. Increased blood pressure due to premenstrual stress is due to increase in peripheral resistance and is mediated by adrenocortical stimulation causing precapillary resistance. This could be due to increase in sympathetic nervous activity or to elevation of circulating catecholamines while other active hormones like renin-angiotensin - aldosterone system also might contribute. Rise in blood pressure due to stress leads to increased epinephrine secretion and this rise in blood pressure is important sympathoadrenal response to physiological stressful experience caused by premenstrual stress. ${ }^{6}$ Hastrup et al. found similar finding of significant rise of pulse rate, systolic and diastolic BP in premenstrual phase.

Hormonal fluctuation like increase level of estradiol and progesterone during premenstrual phase also responsible for premenstrual changes. ${ }^{8}$ Interaction of CNS neurotransmitters \& sex hormones leads to premenstrual stress which shifts ANS toward sympathetic. Most evidences suggest that there is decrease in serotonin and beta-endorphin level during premenstrual phase. These are associated with change in mood and behavioral symptoms. ${ }^{9}$

\section{CONCLUSION}

In our study it was observed that there is increase in autonomic parameters during premenstrual phase showing, sympathetic dominance during premenstrual phase as compared to postmenstrual phase.

\section{ACKNOWLEDGEMENTS}

We would like to thank department of physiology, LTMMC and GH, Sion Mumbai.

Funding: No funding sources

Conflict of interest: None declared

Ethical approval: The study was approved by the institutional ethics committee of, LTMMC and GH, Sion, Mumbai

\section{REFERENCES}

1. Gise LH. Premenstrual syndrome. In: Lameke PD, Pattison J, Marshal JL, Cowley SD, eds. Primary Care of Women $1^{\text {st }}$ ed. East Norwalk: Simon. Schuster Company; 1995: 410-419.

2. Cronje WH, Studd J WW. Premenstrual syndrome and premenstrual dysphoric disorder. Prim Care Clin Office Pract. 2002 Mar;29(1):1-12.

3. Mehta V, Chalranartu AS. Autonomic functions during different phases of menstrual cycle. Indian $\mathbf{J}$ Physiol Pharmacol. 1993;37:56-8.

4. Hines EA, Brown GE. The cold pressor test for measuring the reactability of blood pressure. Am Heart J. 1936;11:1-9.

5. Freyschuss U, Hjemdahl P, Juhlin-Dannfelt A, Linde B. Cardio vascular \& sympathoadrenal response to mental stress influences of blockade. Am J Physiol. 1998;255:H1443-53. 
6. Strauss B, Schutheiss M, Cohen R. Autonomic reactivity in the premenstrual phase. $\mathrm{Br} \mathrm{J}$ Clin Psycho. 1983;22:1-9.

7. Hastrup JL, Light KC, Sen. Differences in cardio vascular stress response modulation as a function of menstrual phase. J Psychosom Res. 1984;28:475-83.

8. Watts JF, Butt WR, Logan Edwards R, Holder G. Hormonal studies in women with premenstrual tension. Br J Obstet Gynecol. 1985;92:247-55.
9. Cunningham J, Yonkers KA, O’Brien S, Eriksson E. Update on research and treatment of premenstrual dysphoric disorder. Harvard Rev Psychiatry. 2009;17(2):120-37.

DOI: $10.5455 / 2320-1770 . i j r \operatorname{cog} 20150428$

Cite this article as: Kale JS, Katole NT. Comparison of autonomic activity between pre and post menstrual period. Int J Reprod Contracept Obstet Gynecol 2015;4:429-31. 